Research letter

\title{
Morphology and biomechanical properties of cerebellar arteries in adults
}

\author{
Olga A. Fomkina ${ }^{1}$, Vladimir N. Nikolenko ${ }^{2}$, Elena V. Chernyshkova ${ }^{1}$ \\ ${ }^{1}$ Saratov State Medical University n.a. V.I. Razumovsky, Saratov, Russia \\ ${ }^{2}$ First Moscow State Medical University n.a. I.M. Sechenov, Moscow, Russia
}

Received 20 March 2016, Accepted 19 April 2016

(C) 2016, Fomkina O.A., Nikolenko V.N., Chernyshkova E.V.

(C) 2016, Russian Open Medical Journal

Abstract: The goal was to analyze the variability of a number of morphometric and biomechanical parameters of cerebellar arteries in adults aged $20-74$ years.

Material and Methods - 179 samples of cerebellar arteries, obtained by autopsy of adults without acute cerebrovascular pathology have been studied; 24 preparations of arterial complexes «arterial circle - cerebral arteries» from scientific collection of Human Anatomy Department of Saratov State Medical University (Saratov, Russia) have been also investigated. Research methods were: preparation, microscopy, experiments on uniaxial longitudinal stretching at a tensile testing machine Tira Test 28005 (TIRA GmbH, Germany). We studied outer diameter, angle of divergence, overall strength and maximal relative deformation of superior (SCA), anterior inferior (AICA) and posterior inferior cerebellar arteries (PICA).

Results and Conclusion - It was revealed that SCA was characterized by the largest diameter and angle of divergence, the most strength and extensibility. AICA and PICA had no significant differences of the studied parameters. It was noted that AICA originated in the lower third part of basilar artery 1.5 times more likely than in the middle third part of this artery.

Keywords: superior cerebellar artery, posterior inferior cerebellar artery, anterior inferior cerebellar artery, angle of divergence

Cite as Fomkina OA, Nikolenko VN, Chernyshkova EV. Morphology and biomechanical properties of cerebellar arteries in adults. Russian Open Medical Journal 2016; 5: e0205.

Correspondence to Olga A. Fomkina. Address: Human Anatomy Department, Saratov State Medical University n.a. V.I. Razumovsky, 112, B. Kazachya St., Saratov, 410012, Russia. Phone: +7 (8452) 66-97-65. E-mail: oafomkina@mail.ru

\section{Introduction}

Scientific literature contains not numerous information about the dimensional characteristics of cerebellar arteries, most of which has been dated back to the second half of the previous century [1-5, etc.]. Not all of the papers indicate the total number of examinations, basic statistic data allowing to evaluate their variability and significance of the differences. Contemporary data on sizes of cerebellar arteries, bilateral variability of an outside diameter and angles of divergence of cerebellum arteries are sporadic [6-8], or present not for all cerebellar arteries $[9,10]$. Biomechanical parameters of cerebellum arteries have not been described in the literature. Meanwhile, knowledge of morphological and biomechanical structural features of cerebellar arteries has a significant general biological meaning from the viewpoint of phylo- and anthropogenetic transformations of cerebrum vessels and maintains an applied orientation, as it is needful for interpretation of some visualization research methods and for modeling circulatory dynamics of a cerebrum.

The goal was to analyze the variability of a number of morphometric and biomechanical parameters of cerebellar arteries in adults aged $20-74$ years.

\section{Material and Methods}

For the study of morphometric parameters of cerebellar arteries we used 24 preparations of arterial complexes «arterial circle - cerebral arteries», made by means of B.K. Ginze method (modified by V.I. Bick) and composing scientific angioneurologic collection of human anatomy department of Saratov State Medical University (Saratov, Russia) (Figure 1). For manufacturing such drugs cerebral arterial vessels together with arachnoid covering were removed and straighten between glasses in their natural position. Outside diameter of cerebellar arteries and distance between divergence place of posterior inferior cerebellar artery (PICA) and mouth of basilar artery (BA) were measured by microscope.

To study deformation and strength properties, 179 samples of cerebellar arteries, obtained by autopsy of adults without visible cerebrovascular pathology, were used. Fence material was carried out in 12 hours after death. Total number of the studied samples: superior cerebellar artery (SCA) - 114, anterior inferior cerebellar artery (AICA) - 44, PICA - 21. During the experiment on uniaxial longitudinal stretching at a tensile testing machine Tira Test 28005 (TIRA GmbH, Germany), we were studying overall strength (maximal effort up to break) and relative deformation of arteries. 


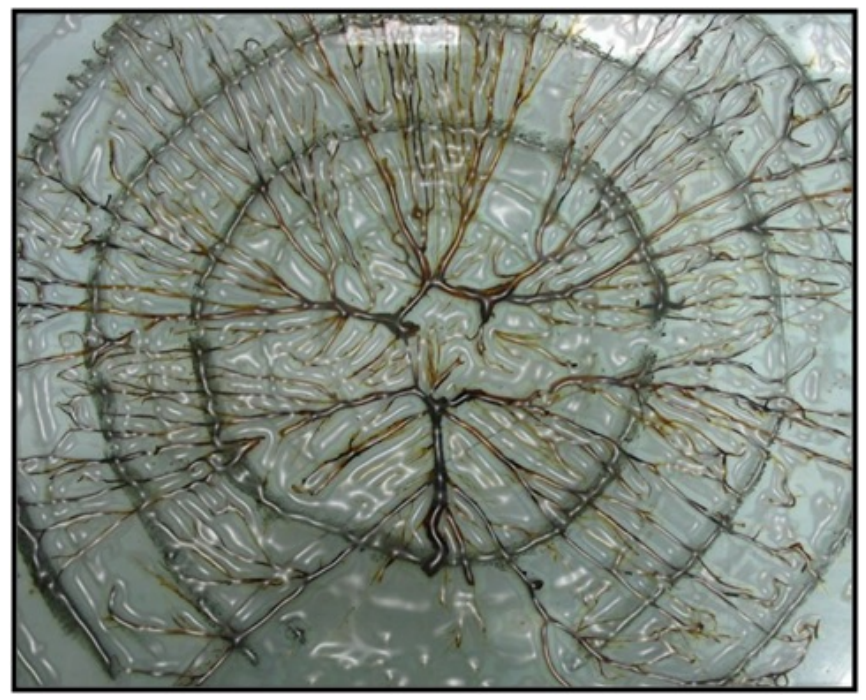

Figure 1. Arterial complex "Arterial circle - cerebral arteries» (Scientific fund of human anatomy department of Saratov State Medical University)

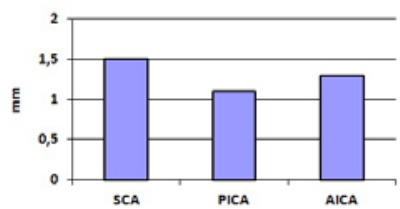

Outside diameter of cerebellar arteries

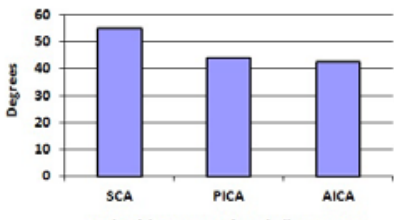

Angle of divergence of cerebellar arteries
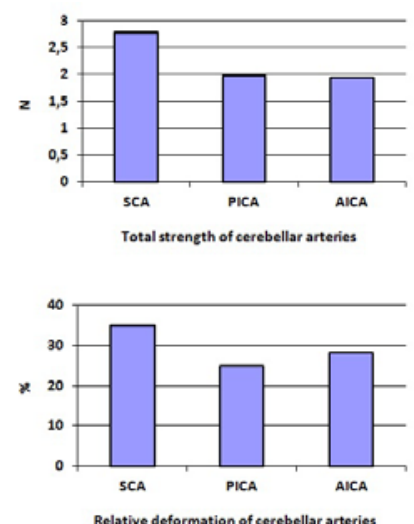

Figure 2. Variability of outside diameter, angle of divergence, total strength and relative deformation of cerebellar arteries

Angles of divergence of cerebellar arteries were measured by computer program «Micrografx Designer 9.0», digital photos of 47 native preparations of cerebrum were imported to this program.

Statistical data processing was conducted by means of computer program Statistica 6.0. Distribution was close to normal. As the variation and statistical parameters, the following parameters were calculated: minimum value ( $\mathrm{min})$, maximum value (max), arithmetic mean (M), error of arithmetic mean (m), standard deviation $(\sigma)$, ratio of variation (Cv). Significance of differences in these groups was assessed by Student's criterion. Statistically significant difference between groups of comparison was considered as $\mathrm{P}<0.05$.

\section{Results}

SCA at all of observations was present from both of the sides and started from anterior part of basilar artery. Doubling of SCA was determined on the right side in $8 \%$, on the left side in $13 \%$ of cases.
SCA is the largest among the other cerebellum arteries (Figure 2). Outside diameter of this artery varies from 0.70 до $2.90 \mathrm{~mm}$, and on an average is $1.50 \pm 0.07 \mathrm{~mm}(\mathrm{n}=53 ; \sigma=0.51 \mathrm{~mm}$; $\mathrm{Cv}=34,7 \%)$. The right and the left SCA were similar in their diameters only in $16 \%$ of the observed cases. In $42 \%$ either the right or the left artery prevailed. Statistically significant bilateral differences were not determined.

Angle of divergence of SCA was in the range of $30.0^{\circ}-92.0^{\circ}$. In $100 \%$ of cases it is asymmetrical and on an average it is $55.11 \pm 2.10^{\circ}$ ( $n=53 ; \sigma=15.36^{\circ} ; C v=27.9 \%$ ). In $74 \%$ of observations this parameter prevailed in the left SCA ( $\left.M \pm m: 57.3 \pm 4.8^{\circ}\right)$, in $26 \%-$ in the right one $\left(\mathrm{M} \pm \mathrm{m}: 52.7 \pm 7.2^{\circ}\right)$. Statistically significant bilateral differences in angle of divergence were not revealed.

Maximum strengthening held by SCA up to its break on an average was $2.77 \pm 0.09 \mathrm{~N}$ ( $n=114$; min-max: $1.00-6.40 \mathrm{~N} ; \sigma=0.93 \mathrm{~N}$; $\mathrm{Cv}=33.5 \%)$. Statistically significant differences for the right $(\mathrm{M} \pm \mathrm{m}$ : $2.84 \pm 0.11 \mathrm{~N}$ ) and the left SCA ( $\pm m$ : $2.70 \pm 0.13 \mathrm{~N}$ ); and also for male $(\mathrm{M} \pm \mathrm{m}: 2.80 \pm 0.10 \mathrm{~N})$ and female $(\mathrm{M} \pm \mathrm{m}: 2.66 \pm 0.19 \mathrm{~N})$ arteries were not recorded.

Value of relative deformation was similar on right and left and varied from 10.8 to $98.3 \%$, on an average it was $35.1 \pm 1.2 \%(n=119$; $\sigma=12.9 \%$; $C v=36.9 \%)$. Wherein male SCA ( $n=83$; min-max: 14.29 98.33\%; $\mathrm{M} \pm \mathrm{m}: \quad 36.92 \pm 1.29 \% ; \quad \sigma=12.65 \% ; \quad \mathrm{CV}=33.8 \%)$ was statistically more valuable $(p<0.01)$ in 1.3 times $(29.5 \%)$ more extensible than female ( $n=36$; min-max: 10.80-58.00\%; $M \pm m$ : 28.49 $\pm 2.48 \%$; $\sigma=12.65 \% ; C v=34.4 \%$ ).

AICA is a permanent present artery. In $33 \%$ of cases it was absent on one of the sides; in $16 \%$ it was absent on both of the sides. In $100 \%$ of observations AICA started form lower (61\%) or middle third of basilar artery (39\%). Wherein, it branched out from the lower third of BA on the right side (79\%), from the middle third part of BA - on the left side (57\%). We didn't mention doubling of the artery.

AICA is the smallest among all of cerebellum arteries. Its outside diameter varies within $0.50-1.70 \mathrm{~mm}$ and on average is $1.09 \pm 0.06 \mathrm{~mm}(\mathrm{n}=32 ; \sigma=0.33 \mathrm{~mm} ; \mathrm{Cv}=30.3 \%)$. The same diameter on both of sides was marked in $8 \%$ of cases, in $83 \%$ prevailed the diameter of the right and in $8 \%$ - of the left AICA. But statistically valuable differences in diameter of the right $(\mathrm{M} \pm \mathrm{m}: 1.18 \pm 0.15 \mathrm{~mm})$ and of the left arteries ( $\mathrm{M} \pm \mathrm{m}: 1.00 \pm 0.11 \mathrm{~mm}$ ) were not noted.

Angle of divergence of AICA varied in the range of $17.0^{\circ}-56.2^{\circ}$, on average it was $44.11 \pm 1.52^{\circ}\left(n=32 ; \sigma=8.62^{\circ} ; C v=19.6 \%\right)$. Angle of divergence of this artery in $100 \%$ of cases was asymmetrical. In $58 \%$ of observations it prevailed on the right ( $\mathrm{M} \pm \mathrm{m}: 44.9 \pm 2.8^{\circ}$ ), in $42 \%$ - on the left side $\left(M \pm m: 43.4 \pm 4.1^{\circ}\right)$. Statistically significant bilateral differences of this parameter were not revealed.

Maximum effort which the artery could withstand before its break was on an average $1.99 \pm 0.09 \mathrm{~N}(\mathrm{n}=36$; min-max: $1.00-3.50$ $\mathrm{N} ; \sigma=0.64 \mathrm{~N} ; \mathrm{Cv}=31.6 \%)$. Statistically significant differences for the right (M $\pm \mathrm{m}: 2.22 \pm 0.13 \mathrm{~N})$ and for the left $(\mathrm{M} \pm \mathrm{m}: 1.79 \pm 0.11 \mathrm{~N})$ AICA, also in male $(\mathrm{M} \pm \mathrm{m}: 2.01 \pm 0.10 \mathrm{~N})$ and female $(1.90 \pm 0.23 \mathrm{~N}$, respectively) were not detected.

Magnitude of relative deformation of AICA was $25.42 \pm 1.01 \%$ ( $n=35 ;$ min-max: $13.20-42.30 \% ; \sigma=7.8 \% ; C v=30.7)$. Wherein, the right AICA (M $\pm m$ : $27.55 \pm 2.02 \%)$ on $16.6 \%(p<0.05)$ was more extensible than the left ( $\mathrm{M} \pm \mathrm{m}: 23.62 \pm 2.02 \%)$. Extensibility of AICA in male $(M \pm m: 26.66 \pm 1.63)$ and female ( $M \pm m: 24.68 \pm 1.42)$ was not significantly different. 
PICA is not also a permanent present artery. PICA was absent: on the right in $4 \%$, on the left - in $1 \%$, on both sides - in $2 \%$ of cases. In 96\% it started from vertebral artery; on the right side it was $2 \mathrm{~mm}$ nearer to mouth of basilar artery. In $4 \%$ of cases PICA began its start from basilar artery. Wherein, at half of observations this artery branched out after basilar artery background, in remaining cases - about $4 \mathrm{~mm}$ from the place of vertebral arteries merger. We did not find the cases of this artery doubling.

Outside diameter of PICA ranged in diapason from 0.35 to $2.10 \mathrm{~mm}$, on an average was $1.32 \pm 0.07 \mathrm{~mm}(\mathrm{n}=45 ; \sigma=0.44 \mathrm{~mm}$; $\mathrm{CV}=33.1 \%$ ). The same diameter on both of the sides the artery had in $14 \%$ of cases, in $50 \%$ prevailed the left and in $36 \%$ the right PICA diameter. However, statistically significant differences in diameter of the right $(\mathrm{M} \pm \mathrm{m}: 1.32 \pm 0.19 \mathrm{~mm})$ and the left arteries $(\mathrm{M} \pm \mathrm{m}$ : $1.33 \pm 0.16 \mathrm{~mm}$ ) were not marked.

Angle of divergence of PICA varied in diapason from $9.0^{\circ}$ to $86.3^{\circ}$, on average it was $42.62 \pm 2.07^{\circ}\left(n=45 ; \sigma=13.75^{\circ} ; C v=32.3 \%\right)$. Angle of divergence of this artery in $100 \%$ of observations was asymmetrical: in $24 \%$ of cases it prevailed on the right $(\mathrm{M} \pm \mathrm{m}$ : $\left.41.1 \pm 5.5^{\circ}\right)$, in $76 \%$ - on the left PICA ( $\pm m$ : $\left.44.1 \pm 5.6^{\circ}\right)$. There were no statistically valuable bilateral differences in this parameter.

Maximum effort which the artery could withstand before its break was on an average $1.94 \pm 0.12 \mathrm{~N}(\mathrm{n}=21$; min-max: 1.20 $3.00 \mathrm{~N} ; \sigma=0.53 \mathrm{~N} ; \mathrm{Cv}=27.2 \%$ ). Statistically significant differences in the right $(\mathrm{M} \pm \mathrm{m}: 2.12 \pm 0.14 \mathrm{~N})$ and in the left $(\mathrm{M} \pm \mathrm{m}: 1.81 \pm 0.16 \mathrm{~N})$ PICA, also as of the mentioned arteries in male $(\mathrm{M} \pm \mathrm{m}$ : $1.89 \pm 0.17 \mathrm{~N})$ and female $(\mathrm{M} \pm \mathrm{m}: 2.01 \pm 0.15 \mathrm{~N})$ were not revealed.

Magnitude of relative deformation of PLCA was $28.23 \pm 1.90 \%$ ( $n=23$; min-max: $12.86-57.27 \% ; \sigma=9.14 \% ; C v=32.4 \%$ ). Statistically significant differences for the right ( $\mathrm{M} \pm \mathrm{m}: 28.21 \pm 3.25 \%)$ and left

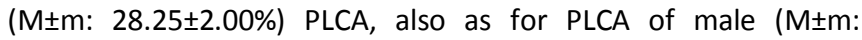
$30.41 \pm 2.96 \mathrm{~N})$ and female $(\mathrm{M} \pm \mathrm{m}: 25.41 \pm 0.90 \mathrm{~N})$ were not detected.

\section{Discussion}

Most of the material available in literature concerning cerebellar arteries has been devoted to their variants and abnormalities. In comparison with other cerebellar arteries, SCA presented in literature has been analyzed rather circumstantially. Permanent presence of SCA and its start from basilar artery are acknowledged by the majority of the studies $[1,3,10]$. We have not found a single case of SCA divergence from a P1-segment of PCA, as it was described by R.N. Lyunkova and V.V. Krylov (2014) [10]. The outside diameter that we have obtained was conformed by the data of I.F. Krupachev and N.N. Metalnikova (1957) [1], as well as J. Lang (1995) [5]. A slightly larger diameter has been received by S.N. Ogneva (1957) [2], V.N. Lyunkova and V.V. Krylov (2014) [10]. In scientific papers the angle of divergence of SCA has been described as a straight $(900)[1,11]$, however this fact has no confirmation in the present study.

AICA has fewer descriptions in the literature. I.F. Krupachev (1957) observed absence of AICA in 2\% [1], S.N. Ogneva (1950) - in $4 \%$ of cases [2]. Consequently, cases of AICA aplasia have been revealed more often than it was mentioned in literature. AICA as one of cerebellar artery is characterized by a small diameter; this has confirmation in other authors' proceedings [1, 3]. According to J. Lang (1995) [5], the outside diameter of this artery is larger (on an average more than $0.6 \mathrm{~mm}$ ) unlike our data.
Our study demonstrated that PICA was rarely absent than it has been reported in literature $[4,11]$. The majority of researchers have described an outside surface of the upper third part of a vertebral artery and rarely its lower third part of a basilar artery as the start point of PICA $[1-3,9,11]$. According to L.V. Pazhinsky et al. (2007) [7], who have studied 90 anatomic preparations of a human cerebrum, PICA has always its divergence from a vertebral artery. We observed this phenomenon in $96 \%$ of cases and in $4 \%-$ it had divergence from a basilar artery. Data concerning outside diameter of PICA correspond to the information form scientific literature [3]. In the proceeding of A.G. Vinokurov et al. (2011) [8] diameter of the left PICA is 1.8 time more than of the right, 2.3 $\mathrm{mm}$ and $1.3 \mathrm{~mm}$ respectively. Our material didn't confirm the presence of significant bilateral differences.

Information about deformation and strength properties of wall of cerebellar arteries has not been discussed in scientific literature. Thereby, there is no opportunity to compare our data with the data of other researchers.

\section{Conclusion}

Thus, the upper cerebellar arteries are characterized by the largest outside diameter, angle of divergence, the most strength and extensibility. Doubling of these vessels can be observed more often. Lower anterior and posterior lower cerebellar arteries have no significant differences in the studied parameters. It is noted that lower anterior cerebellar arteries start from the lower third part of a basilar artery 1.5 times more often than from the middle third part. The received data about functional anatomy of cerebellar arteries could be useful for modeling of bloodstream and for optimization of intravascular surgery.

Conflict of interest: none declared.

\section{References}

1. Krupachev IF, Metalnikova NN. Villiziyev a circle. In: Multivolume guide to neurology. Moscow, Russia: Medgiz, 1957; Vol. 1, book 2: 326-329. Russian

2. Ogneva SM. Blood vessels of a medulla oblongata and a pons. In: Multivolume guide to neurology. Moscow, Russia: Medgiz, 1957; Vol. 1: 373-380. Russian

3. Antonov IP, Gitkina LS. Vertebro-bazilyar strokes. Minsk, Belarus, 1977; 240 p. Russian

4. Mitterwallner F. Variation statistische untersuchungen on den basalen Hirngefassen. Acta Anat 1955; (2): 51-87.

5. Lang J. Skull base end related structures. Stuttgart, New York, 1995 $345 \mathrm{p}$.

6. Fomkina OA. Morphology of intra cranial parts of vertebral arteries, a basilar artery, cerebellar arteries and posterior cerebral arteries at adults of different age and a floor. PhD dissertation. Volgograd, Russia, 2006; 198 p. Russian

7. Pazhinsky LV, Gayvoronsky IV, Gayvoronsky AI, Bola KW. Alternative anatomy of arteries of a brain of the person. Medicine 21st Century 2007; 6(7): 72-78. Russian

8. Vinokurov AG, Krylov VV, Hutorna NV, Dobrovolsky GF. Surgical anatomy of arteries of brain. In: Surgery of aneurisms of a brain. Moscow, Russia, 2011; Vol. 1; 432 p. Russian

9. Lepshokov MH, Tkachyov VV, Usachev AA, Kran OI, Muzlayev GG. Radiological anatomy of vertebral, back lower cerebellar and occipital arteries. Kuban Scientific Medical Bulletin 2014; (7): 117-122. Russian

10. Lyunkova VN, Krylov VV. Individual anatomic variability of the top cerebellar artery. Neurosurgery 2014; (2): 17-32. Russian 
11. Grigorovsky IM. Materials to surgery of a back cranial pole. Moscow and Leninrad, Russia: Medgiz, 1940; 146 p. Russian

\section{Authors:}

Olga A. Fomkina - MD, PhD, Assistant, Human Anatomy Department, Saratov State Medical University n.a. V.I. Razumovsky, Saratov, Russia.

Vladimir N. Nikolenko - MD, D.Sc., Professor, Head of Human Anatomy Department, First Moscow State Medical University n.a. I.M. Sechenov, Moscow, Russia.

Elena V. Chernyshkova - D.Sc., Assistant Professor, Head of Foreign Languages Department, Saratov State Medical University n.a. V.I. Razumovsky, Saratov, Russia. 